Pub. 554

\title{
Avaliação da atividade antimicrobiana in vitro da planta Bryophyllum pinnatum Kurz ("Folha-da-fortuna") colhida em Várzea Grande, Mato Grosso/Brazil
}

\author{
In vitro antimicrobial activity of Bryophyllum pinnatum ("Folha-da-fortuna") leaves from \\ Várzea Grande, Mato Grosso/Brazil
}

\section{Aline Conceição Schmitt ${ }^{1}$, Arleana Bom Parto Ferreira de Almeida ${ }^{2}$, Tatiane Andrea da Silveira ${ }^{2}$, Chrissie Takemura Iwakura ${ }^{2}$, Karoline Flores Mendes ${ }^{2} \&$ Maria Cristina da Silva ${ }^{2}$}

\begin{abstract}
RESUMO
As folhas de Bryophyllum pinnatum Kurz. ("Folha-da-fortuna"), Crassulaceae, têm sido usadas na medicina popular como emolientes para furúnculos, em queimaduras ou outros ferimentos, além de problemas respiratórios e gástricos. O trabalho teve por objetivo avaliar a atividade antimicrobiana do decocto de B. pinnatum Kurz. (Crassulaceae), sobre bactérias Gram positivas e Gram negativas. A avaliação da atividade antimicrobiana das folhas da planta em estudo foi realizada utilizando decocto, através da técnica de diluição em tubos, frente a três bactérias isoladas de cães com lesões de pele (Staphylococcus sp., Pseudomonas aeruginosa e Streptococcus sp.) e uma de fezes de suínos (Escherichia coli). O decocto apresentou, após 30 minutos de incubação, capacidade de inibir o crescimento bacteriano na concentração de $4 \mathrm{mg} / \mathrm{mL}$ para Staphylococcus sp. Quando avaliado frente ao Streptococcus sp., não foi observada turvação do meio, embora tenha se observado um precipitado em todos os tubos. Na análise realizada com $P$. aeruginosa e $E$. coli, não foi observada inibição do crescimento em nenhuma diluição e tempo de ação do decocto. Os resultados demostraram uma ação antimicrobiana do decocto da folha de Bryophillum pinnatum Kurz. sobre bactérias Gram positivas.
\end{abstract}

Descritores: antimicrobianos, medicina popular, Crassulaceae, Bryophyllum pinnatum.

\section{ABSTRACT}

The leaves of Bryophyllum pinnatum Kurz. ("Folha-da-fortuna"), Crassulaceae have been used in folk medicine to treat skin infections, burning, respiratory and gastric disorders. The objective of this work was to evaluate the antimicrobial activity of $B$. pinnatum Kurz. (Crassulaceae), decoct against Gram positive and negative bacteria. This evaluation was carried out using the dilution tube method. Staphylococcus sp., Pseudomonas aeruginosa, Streptococcus sp. and Escherichia coli were used in this research and all bacteria were isolated from clinical isolates. The decoct was capable of inhibit the development of Staphylococcus sp. after 30 minutes of incubation period at $4 \mathrm{mg} / \mathrm{mL}$. Tubes containing Streptococcus sp. did not show turbidity, even though a precipitated was seen in all concentration. Pseudomonas aeruginosa and Escherichia coli were not susceptible to the decoct. The results showed an antimicrobial activity of Bryophyllum pinnatum Kurz. leaves decoct against Gram positive bacteria.

Key words: antimicrobial ativity, folk medicine, Crassulaceae, Bryophyllum pinnatum.

Departamento de Clínica Médica Veterinária, Faculdade de Veterinária, Universidade Federal do Mato Grosso (UFMT). ${ }^{2}$ Graduandos de Medicina Veterinária - UFMT. CORRESPONDÊNCIA: (Endereço atual) A. C. Schmitt [e-mail: alinecs@ uesc.br ; Fax +73 680 5230]. Universidade Estadual de Santa Cruz, Departamento de Ciências Biológicas. Rodovia Ilhéus/Itabuna km 16, s/n; 45662-000 Ilhéus, BA - Brasil. 


\section{INTRODUÇÃO}

O uso de plantas como recurso terapêutico vem sendo descrito em toda história da humanidade. O homem sempre buscou nelas "soluções para todos os seus males" [3,7]. Sendo assim, estudos vêm sendo realizados com o intuito de comprovar a ação antimicrobiana de plantas utilizadas na cultura popular. Avancini et al. [2] analisando o decocto da planta Bacharis trimera ("Carqueja") verificaram uma marcada ação nas bactérias Gram positivas mas diferenças de sensibilidade das Gram negativas. Esses resultados confirmaram a ação da planta como antiséptico usado na cultura popular. Da mesma maneira, Nascimento et al. [5] relataram a ação antimicrobiana de extratos de plantas usadas na cultura popular como o "alecrim" e "erva-cidreira" frente a bactérias sensíveis e resistentes à antibióticos sintéticos. Os autores verificaram que em alguns casos houve sinergismo entre os antibióticos e os extratos usados, possibilitando que antibióticos ineficazes apresentassem ação sobre bactérias resistentes.

As folhas de Bryophyllum pinnatum Kurz. ("Folha-da-fortuna"), Crassulaceae, têm sido usadas na medicina popular como emolientes para furúnculos, em queimaduras ou outros ferimentos, além de problemas respiratórios e gástricos. Além disso, estudos envolvendo avaliação antimicrobiana e análise dos constituintes químicos vêm sendo realizados para confirmar sua ação na medicina popular $[1,4]$.

$\mathrm{O}$ uso de plantas medicinais no estado do Mato Grosso tem sido amplamente difundido devido à dificuldade de acesso da maioria da população aos postos de atendimento de saúde e a aspectos culturais e geográficos, caracterizado pela diversidade da flora nativa do cerrado [6]. A etnofarmacologia também tem sido aplicada para o tratamento das enfermidades animais, não somente no Brasil como em outros países [4].

Tendo em vista a grande difusão de uso das plantas medicinais na cultura popular, o seu reconhecimento internacional cada vez maior em relação ao potencial terapêutico das mesmas e o uso da "Folhada-fortuna" na medicina popular local, este trabalho teve por objetivo realizar a avaliação da atividade antimicrobiana da planta $B$. pinnatum frente às bactérias Gram positivas e negativas, com o intuito de validar o seu uso no estado de Mato Grosso, Brasil.

\section{MATERIAIS E MÉTODOS}

\section{Planta e decocto}

Amostras da planta Bryophillum pinnatum foram cole-tadas no verão (fevereiro de 2002) em uma localidade afastada do centro urbano, situada dentro do município de Várzea Grande, Mato Grosso, de vegetação espontânea e livre de contaminantes quími$\cos$. A exsicata da planta foi encaminhada ao Instituto de Biociências da Universidade Federal do Mato Grosso (UFMT), para identificação taxonômica. As folhas foram secas à sombra, em temperatura ambiente e sem umidade, por um período de 30 dias.

O decocto foi obtido esgotando-se $40 \mathrm{~g}$ da planta em $1000 \mathrm{~mL}$ de água destilada e levada à cocção em Erlenmeyer coberto, por 15 minutos.

\section{Bactérias}

Como inóculos Gram positivos foram utilizados Staphylococcus sp. e Streptococcus sp. e como Gram negativos Pseudomonas sp. (lesão de pele em cães) e Escherichia coli (fezes de suínos), oriundos de casos clínicos enviados ao Laboratório de Microbiologia Veterinária da UFMT. Bactérias dos gêneros Staphylococcus, Streptococcus e Pseudomonas são responsáveis por lesões de pele em animais e que com o uso constante de antibacterianos pode ocorrer a seleção de estirpes resistentes tornando as infecções crônicas e de difícil cura. Já a $E$. coli é um agente de grande importância principalmente para a suinocultura, uma vez que o uso contínuo de antibióticos nas rações animais com seleção de amostras bacterianas resistentes e a susceptibilidade desses animais a algumas cepas de E. coli podem levar a perdas econômicas significativas nesta produção.

\section{Titulação Bacteriana}

Após a identificação das bactérias, foi feita a contagem bacteriana pelo método de diluição em tubos múltiplos até a diluição em que se visualizasse, através do plaqueamento em Ágar Mueller-Hinton ${ }^{\circledR 1}$, 100 unidades formadoras de colônias, exceto para Streptococcus sp., que era incubado apenas em caldo Brain Infusion Heart ${ }^{2}\left(\mathrm{BHI}^{\circledR}\right)$.

Para a titulação de Staphylococcus sp., P. aeruginosa e E. coli, as bactérias eram cultivadas 
previamente em caldo $\mathrm{BHI}$ por 6 horas, a $36^{\circ} \mathrm{C}$ e semeadas em Ágar Mueller-Hinton, sendo incubadas por 24 horas a $36^{\circ} \mathrm{C}$ para posterior leitura.

\section{Atividade Antimicrobiana}

Para a avaliação da atividade antimicrobiana foram utilizados tubos de ensaio com $5 \mathrm{~mL}$ do decocto cada, utilizando quatro diluições do mesmo nas proporções de 8, 4, 2 e 1mg/mL.

A cada diluição foi adicionado $0,1 \mathrm{~mL}$ do inóculo, e em intervalos de 5, 10, 15 e 30 minutos de contato foi retirado um alíquota de $0,1 \mathrm{~mL}$. Esta foi inoculada em $0,9 \mathrm{~mL}$ de caldo $\mathrm{BHI}^{\circledR}$, levada à estufa a $36^{\circ} \mathrm{C}$ para ser feita avaliação de turvação após $6 \mathrm{~h}$. Após este intervalo foi feito o plaqueamento em Ágar Mueller-Hinton ${ }^{\circledR}$. Depois de $18 \mathrm{~h}$ de incubação, foi realizada a verificação do crescimento bacteriano na placa. A avaliação da ação antimicrobiana sobre Streptococcus sp. foi realizada observando-se apenas a turvação do meio líquido após 24h de incubação, na estufa a $36^{\circ} \mathrm{C}$. Todos os testes foram repetidos duas vezes para confirmação dos resultados.

\section{RESULTADOS}

Os resultados (Tabela 1) indicaram que o decocto das folhas de B. pinnatum promoveu inibição do crescimento bacteriano de Staphylococcus sp. na concentração de $8 \mathrm{mg} / \mathrm{mL}$ e $1 \mathrm{mg} / \mathrm{mL}$ após 10 minutos de incubação, mas houve crescimento bacteriano quando mantido por mais tempo (15 e 30 minutos). Já, na concentração de $4 \mathrm{mg} / \mathrm{mL}$, o decocto mostrou diminuição da população bacteriana de Staphylococcus sp. ao longo do tempo, ocorrendo inibição total após 30 minutos de incubação. Em relação ao Streptococcus sp. não foi observada turvação do meio, embora tenha se observado um precipitado em todos os tubos.
$\mathrm{Na}$ análise realizada com $P$. aeruginosa e $E$. coli não foi observada inibição do crescimento em nenhuma diluição e tempo de ação do decocto, sendo que os tubos inoculados com estas bactérias e incubadas com decocto, após 24 horas, mostraram turbidez em todas as concentrações.

\section{DISCUSSÃO}

Os resultados evidenciaram a susceptibilidade do isolado de Staphylococcus sp. utilizado, o que concorda com as observações feitas por Akinpelu [1] que utilizou um extrato metanólico da mesma planta. A maior ação do decocto a $4 \mathrm{mg} / \mathrm{mL}$ demonstra uma provável ação específica de algumas substâncias presentes nas folhas de $B$. pinnatum dependentes da solubilidade em água a determinada concentração, o que provavelmente reflete o modo de uso na medicina popular onde os "curandeiros" normalmente aplicam "posologias específicas" para cada planta.

Em relação ao mesmo decocto, bactérias Gram negativas como E. coli e $P$. aeruginosa, apresentaram resistência, configurando uma situação similar à encontrada por Akinpelu [1]. Esta diferença de atividade pemite supor que existam substâncias especificamnete ativas contra as bactérias Gram positivas.

A atividade antimicrobiana do decocto das folhas de B. pinnatum sobre Streptococcus sp., caracterizada pela ausência de turvação do meio, causou uma diminuição do crescimento bacteriano quando comparado ao tubo controle. A ausência de turvação do meio aliada à formação de um precipitado nos tubos contendo decocto nos sugere uma ação sobre componentes protéicos bacterianos das substâncias presentes, como por exemplos os taninos.

Neste trabalho não foi realizada análise fitoquímica, mas a presença de algumas substâncias como

Tabela 1. Avaliação da atividade antimicrobiana das diversas concentrações do decocto deBryophyllum pinnatum frente a bactérias Gram positivas e negativas após 5, 10, 15 e 30 minutos de contato

\begin{tabular}{|c|c|c|c|c|c|c|c|c|c|c|c|c|c|c|c|c|}
\hline \multirow{3}{*}{ Bactérias } & \multicolumn{16}{|c|}{ Decocto de Bryophyllum pinnatum } \\
\hline & \multicolumn{4}{|c|}{$8 \mathrm{mg} / \mathrm{mL}$} & \multicolumn{4}{|c|}{$4 \mathrm{mg} / \mathrm{mL}$} & \multicolumn{4}{|c|}{$2 \mathrm{mg} / \mathrm{mL}$} & \multicolumn{4}{|c|}{$1 \mathrm{mg} / \mathrm{mL}$} \\
\hline & 5 & 10 & 15 & 30 & 5 & 10 & 15 & 30 & 5 & 10 & 15 & 30 & 5 & 10 & 15 & 30 \\
\hline Staphylococcus sp & ++ & - & ++ & + & ++ & ++ & + & - & - & ++ & ++ & ++ & ++ & - & ++ & ++ \\
\hline Streptococcus sp & - & - & - & - & - & - & - & - & + & + & - & - & - & - & - & - \\
\hline Escherichia coli & +++ & +++ & +++ & +++ & +++ & +++ & +++ & +++ & +++ & +++ & ++ & +++ & +++ & ++ & +++ & +++ \\
\hline$P$. aeruginosa & ++ & ++ & ++ & ++ & ++ & + & ++ & ++ & ++ & + & + & + & ++ & + & + & + \\
\hline
\end{tabular}


Schmitt A.C., Almeida A.B.P.F., Silveira T.A., I wakura C.T., M endes K.F. \& Silva M.C. 2003. Avaliação da atividade antimicrobiana in vitro da planta Bryophyllum pinnatum kurz ("folha-da-fortuna")... Acta Scientiae Veterinariae. 31: 55-58.

alcalóides e taninos tem sido previamente relatada para esta planta [8]. O uso de bactérias oriundas de situaçõesproblema, neste estudo, proporcionou resultados mais próximos da realidade, no que diz respeito ao uso de outros fármacos, e corroborou com os resultados obtidos em experimentos que utilizavam amostras laboratoriais [1].

\section{CONCLUSÃO}

Os resultados obtidos sugerem que existem substâncias com atividade antimicrobiana nas folhas de Bryophillum pinnatum, que atuam seletivamente sobre bactérias Gram positivas causadoras de lesões de pele, justificando assim a sua popularidade na etnomedicina mato-grossense.

\section{NOTAS INFORMATIVAS}

${ }^{1}$ Ágar Mueller Hinton ${ }^{\circledR}$ - Merck, Darmstadt, Germany $-1.05437$

${ }^{2}$ Brain Heart Infusion ${ }^{\circledR}(\mathrm{BHI})-$ BBL Becton Dickinson, Cockeysville, USA - 915622

\section{REFERÊNCIAS}

1 Akinpelu D. A. 2000. Antimicrobial activity of Bryophyllum pinnatum leaves. Fitoterapia. 71: 193-194.

2 Avancini C. A. M., Wiest J. M. \& Mundstock E. 2000. Atividade bacteriostática e bactericida do decocto de Baccharis trimera (Less.) D. C., Compositae, carqueja, como desinfetante ou anti-séptico. Arquivos Brasileiros de Medicina Veterinária e Zootecnia. 52: 230-234.

3 Corrêa A. D., Siqueira-Batista R. \& Quintas L.E. 2001. Plantas Medicinais. Do Cultivo à Terapêutica. 4 ed. Vozes: Rio de Janeiro, 264 p.

4 Lans C. \& Brown G. 1998. Observation on ethnoveterinary medicines in Trinidad and Tobago. Preventive Veterinary Medicine. 35: 125-142.

5 Nascimento G. G. F., Locatelli J., Freitas P. C. \& Silva G.L. 2000. Antibacterial activity of plant extracts and phytochemicals on antibiotic-resistant bacteria. Brazilian Journal of Microbiology. 31: 247-256.

6 Neto G.G. \& Moraes E.A.M. 2001. Flora medicinal do cerrado do leste mato-grossense: um estudo etnobotânico. I. Primavera do Leste, Poxoréo e Dom Aquino. Anais do IX Encontro de Iniciação Científica UFMT (Cuiabá, Brasil). p. 235.

7 Sá E. N. M. 1999. Plantas Medicinais: Um Ambiente Digital de Estudo Elizabete Novaes Marques de Sá. [cited 2002, Mar]. Disponível em URL: www.geocities.com/plantas_medicinais.

8 Stevens J. F., Hart K. T., Van Ham R.C.H.J., Elema E. T., Van den Ent M.M.V.X., Wildeboer M. \& Zwaving J.H. 1995. Distribution of alkaloids and tannins in the Crassulaceae. Biochemical Systematics and Ecology. 23: 157-165. 